\title{
An in Vitro Evaluation of the Antimicrobial Effectiveness of Alginate-Based Metronidazole Gel against Aggregatibacter Actinomycetemcomitans
}

\author{
Martina Amalia $^{1^{*}}$, Irma Ervina ${ }^{1}$, Hakim Bangun ${ }^{2}$ \\ ${ }^{1}$ Department of Periodontics, Faculty of Dentistry, Universitas Sumatera Utara, Medan, \\ Indonesia. \\ ${ }^{2}$ Department of Pharmaceutical Technology, Faculty of Pharmacy, Universitas Sumatera Utara, \\ Medan, Indonesia. \\ *Email: martina.lia03@gmail.com
}

\begin{abstract}
This study was to analyze the effect of alginate based metronidazole gel in inhibiting A. actinomycetemcomitans bacteria growth with in vitro evaluation. Alginate-based gel used in this study contains metronidazole $15 \%, 25 \%$, and $25 \%$ metronidazole non-alginate based gel as a comparison. The bacteria used were a pure culture of A. actinomycetemcomitans (ATCC 29522), cultured in Tryptic Soy Agar (TSA) media. Bacteria test was done by placing the metronidazole gel into TSA media that contained bacteria which was put on the disc paper with the aid of sterile tweezers, and $100 \mu 1$ of gel metronidazole was dripped on the disc paper after that TSA media was incubated at $370 \mathrm{C}$ for 24 hours. Measurement of the inhibit zone diameter was observed daily for three days using callipers. The average diameter of inhibition zone of $15 \%, 25 \%$ metronidazole alginate-based gel and $25 \%$ metronidazole non-alginate based gel towards A. actinomycetemcomitans were 15.33 $\mathrm{mm}, 16.67 \mathrm{~mm}$ and $15.33 \mathrm{~mm}$. There was no significant difference between day one and three on $15 \%$ and $25 \%$ alginate based metronidazole gel, except for non-alginate-based metronidazole gel there was a significant difference between day 1, 2 and 3 . The result suggested that $15 \%, 25 \%$ alginate based and $25 \%$ metronidazole non-alginate-based metronidazole gel has a strong influence towards A. actinomycetemcomitans bacteria.
\end{abstract}

Keywords: metronidazole gel, alginate, Aggregatibacter actinomycetemcomitans

\section{Introduction}

Periodontal diseases are a group of inflammatory conditions that affect the tissues surrounding and supporting the teeth. They are caused by bacteria, thereby resulting in a host inflammatory response [1]. The aetiology of the disease is multifactorial. Bacterial deposits play an essential role in the pathogenesis of the disease. 2 Periodontal disease-causing bacteria accumulate in the subgingival plaque. The latter predominantly comprises several genera of anaerobic Gram-negative rods, including Porphyromonas gingivalis, Prevotella intermedia, Fusobacterium nucleatum, Bacteroides spp., Selenemonas spp., Tannerella fosrythia, Treponema denticola, and Aggregatibacter actinomycetemcomitans [2,3]. 
It has frequently been claimed that the mechanical debridement of deep periodontal pockets is not always completely effective. Remaining deposits lead to the inadequate suppression or elimination of pathogenic agents. Accordingly, the use of antibiotics or antimicrobial agents is recommended as an adjunct in the treatment of periodontal diseases; especially in light of the infective nature of periodontitis [4]. The delivery of a local antibiotic directly into the periodontal pocket via subgingival application for achieves a greater, more potent concentration of the drug than its systemic administration [5].

Metronidazole has broad-spectrum antimicrobial activity against protozoan and anaerobic bacterial infections. Antimicrobial metronidazole is currently one of the most widely used antibacterial compounds in the treatment of periodontal disease [6]. Sodium alginate is a natural polymer, as well as being biocompatible and biodegradable. Bangun reported that ointment with an alginate base was highly hydrophilic. Alginate has pseudoplastic rheology and non-irritating properties [7]. Bangun et al. also found that a $25 \%$ alginate-based metronidazole periodontal gel formulation had excellent antibacterial effectiveness [8].

Thus, the current study objective was to determine and analyse the effectiveness of an alginate-based metronidazole gel in inhibiting the growth of A. actinomycetemcomitans bacteria in vitro.

\section{Materials and Method}

The sample used in this study was a pure culture of A. actinomycetemcomitans (ATCC 29522), originating from the Tropical Disease Center Laboratory, Universitas Airlangga, Surabaya, Indonesia, and cultured with trypticase soy agar (TSA). An alginatebased metronidazole gel was made according to the described preparation method by Bangun. The specific formulations are shown in Table 1.

Table 1. Formulations of metronidazole gel.

\begin{tabular}{|l|c|c|}
\hline Materials & $\begin{array}{c}\text { 15\% alginate base } \\
\text { metronidazole gel }\end{array}$ & $\begin{array}{c}\text { 25\% alginate base } \\
\text { metronidazole gel }\end{array}$ \\
\hline Metronidazole $(\mathrm{g})$ & 15 & 25 \\
\hline Na Alginate $(\mathrm{g})$ & 0.75 & 0.75 \\
\hline Ca chloride $(\mathrm{g})$ & 0.05 & 0.05 \\
\hline Glycerol $(\mathrm{g})$ & 50 & 50 \\
\hline CO2-free distilled water $(\mathrm{g})$ & $\mathrm{ad} 100$ & $\mathrm{ad} 100$ \\
\hline
\end{tabular}

Preparation of the metronidazole gel was performed aseptically in a laminar air flow cabinet. The required tools and materials were sterilised in an autoclave. Every material was weighed accurately. The metronidazole was finely ground and mixed with calcium chloride that had been dissolved in $\mathrm{CO} 2$-free distilled water. Sodium alginate was also finely ground, and glycerol was slowly added to it until a homogenous mixture was obtained. The calcium chloride solution was then slowly added to the sodium alginate mixture until viscous and a stiff gel mass was formed. The powdered metronidazole was added to the gel mass until the mixture was of an even consistency. The prepared gel stood for eight hours prior to use.

Twelve grams of the powdered TSA, the medium for the bacterial growth, were dissolved in $240 \mathrm{ml}$ of distilled water in a $20 \mathrm{ml}$ Petri dish, then brought to boil in a 
magnetic hotplate stirrer. The mixture was then sterilised in an autoclave for 15 minutes by air pressure at a temperature of $121{ }^{\circ} \mathrm{C}$. Once sterilised, the media was stored in the refrigerator. When needed, it was reheated to boiling point, then poured into a Petri dish and allowed to cool. The samples were examined in an anaerobic atmosphere in the $\mathrm{CO} 2$ incubator. A disc paper was placed in the bacteria-containing TSA media with the help of sterile tweezers then disc paper dripped $100 \mu \mathrm{l}$ of metronidazole using a micropipette. This was performed three times. The media was then placed in the incubator at $36-37{ }^{\circ} \mathrm{C}$ for $18-24$ hours. Measurement the diameter of the clear zone (inhibit area) was done daily for three days observation by the agar disc diffusion method to A. actinomycetemcomitans. The results of the in vitro evaluation of the antimicrobial effectiveness of the alginate-based metronidazole gel were analysed by using one-way analysis of variance.

\section{Results}

\subsection{The antimicrobial effectiveness of the alginate-based metronidazole gel} against Aggregatibacter actinomycetemcomitans

The clear zones that formed in the TSA media indicated the area of inhibition or antibacterial efficacy of the metronidazole gel that was used at differening strengths, i.e., $15 \%$ and $25 \%$ alginate-based and $25 \%$ non-alginate-based metronidazole gel. Of all the gels, the $25 \%$ alginate-based metronidazole gel was demonstrated to be the most effective and $25 \%$ non-alginate was the least effective in inhibiting the growth of A.actinomycetemcomitans bacteria (Fig 1).
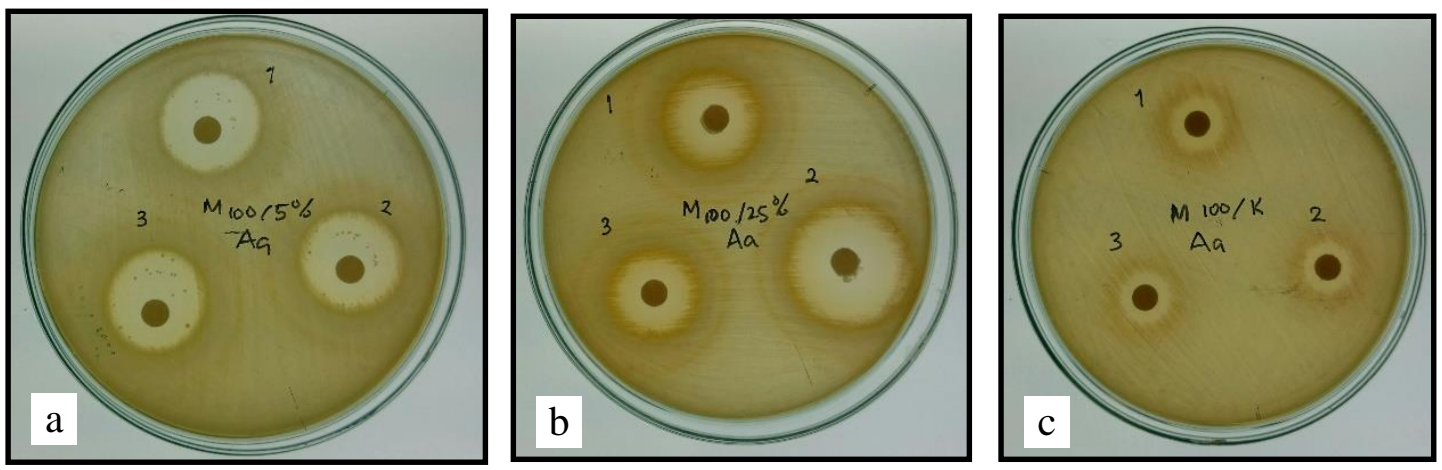

Fig. 1. The clear zone of metronidazole gel against A.actinomycetemcomitans. a) $15 \%$ alginate-based metronidazole gel, b) $25 \%$ alginate-based metronidazole gel, c) Non-alginate based metronidazole gel.

The average diameter of the zone of inhibition formed by the $15 \%$ and $25 \%$ alginate-based metronidazole gel, and by the $25 \%$ non-alginate metronidazole gel on A.actinomycetemcomitans bacteria in three days observation can be seen in the following table (Table 2). 
Table 2. The average diameter of the zone of inhibition made by each metron dazole gel against A.actinomycetemcomitans in three days observation.

\begin{tabular}{|c|c|}
\hline Metronidazole gel & Average $(\ddot{\mathbf{x}})(\mathbf{m m})$ \\
\hline & $15.33 \pm 2.08$ \\
\multirow{2}{*}{ 15\% alginate-based metronidazole gel } & $15.33 \pm 2.08$ \\
& $15.33 \pm 2.08$ \\
\hline \multirow{2}{*}{ 25\% alginate-based metronidazole gel } & $16.67 \pm 2.89$ \\
& $16.67 \pm 2.89$ \\
& $16.67 \pm 2.89$ \\
\hline \multirow{2}{*}{ 25\% non-alginate metronidazole gel } & $11.67 \pm 0.58$ \\
& $15.33 \pm 2.08$ \\
& $15.33 \pm 2.08$ \\
\hline
\end{tabular}

The difference in the inhibition of A. actinomycetemcomitans by the respective metronidazole gels did not reach statitstical significance (Table 3).

Table 3. The difference diameter of the zone inhibition each metronidazole gel against A.actinomycetemcomitans.

\begin{tabular}{|c|c|c|}
\hline \multirow{2}{*}{ Metronidazole gel } & \multicolumn{2}{|c|}{ p value } \\
\cline { 2 - 3 } & $\begin{array}{c}\mathbf{2 5 \%} \text { alginate base } \\
\text { metronidazole gel }\end{array}$ & $\begin{array}{c}\mathbf{2 5 \%} \text { non alginate base } \\
\text { metronidazole gel }\end{array}$ \\
\hline $15 \%$ alginate base metronidazole gel & 0.52 & 0.52 \\
\hline $25 \%$ alginate base metronidazole gel & & 1.00 \\
\hline
\end{tabular}

ANOVA test

$(*)$ significant $\mathrm{p}<0.05$

\section{Discussion}

A clear circular zone around the paper disc in the TSA media was demonstrated following the application of the three gels and indicated the antibacterial efficacy of each drug. The mean measurement of $\geqslant 15 \mathrm{~mm}$ for the gels showed that the drugs had a strong inhibiting effect on A. actinomycetemcomitans bacteria. According to Davis and Stout, if the zone of inhibition is $\leqslant 5 \mathrm{~mm}$, the inhibition activity is considered to be weak. Inhibition activity is thought to be moderate, high and excellent when the area of inhibition is $5-10 \mathrm{~mm}, 10-19 \mathrm{~mm}$ and $\geqslant 20 \mathrm{~mm}$, respectively [9]. These test results correspond with those in the study by Bangun et al. in which the inhibitory effect of periodontal metronidazole gel against $\mathrm{S}$. aureus bacteria was evaluated. It was shown in that study that periodontal metronidazole gel could be formulated using an alginate base, which has good antibacterial activity, is stable for three months at room temperature and has a powerful inhibitory effect on Streptococcus aureus bacteria [8].

The systemic administration of metronidazole effectively killed bacteria and anaerobes, such P. gingivalis and P. intermedia, while metronidazole was demonstrated to inhibt A. actinomycetemcomitans bacteria when it was combined with a second antibiotic in other research [10].

Metronidazole gel was nevertheless effective in inhibiting the growth of A. actinomycetemcomitans bacteria on its own in the current study. This is probably because the local administration of a drug results in a higher drug concentration in the 
applied region, compared to what can be achieved with systemic administration. It has been observed that locally administered medication may be 100 times more effective than systemic administration which will reduce the total dose of more than 400 times that given to the patient to avoid the development of drug resistence [5].

Fifteen percent and 25\% alginate-based metronidazole gel were evaluated in the current study. Alginate is a natural polysaccharide material obtained from brown algae (Phaeophyceae). It is also non-toxic, non-allergenic and biodegradable. When it comes into contact with body tissue, it decomposes into a pure sugar and is absorbed [7]. Alginate is not water soluble, so it is used in sodium and potassium salt forms for industrial applications. Sodium alginate assumes a gel form with the addition of a calcium salt solution, i.e., calcium gluconate, tartrate and citrate. Gel formation results from the chelation of L-guluronate chains and calcium ions [8]. Sodium alginate is the sodium salt form of alginic acid, which is highly hydrophilic and forms a gel when combined with calcium ions. It dissolves slowly in water, forming a viscous solution that is not soluble in ethanol nor ether [7].

Bangun et al. created an alginate-based metronidazole gel formulation to test its efficacy in inhibiting S. aureus bacteria [8]. Based on the results of their research, we elected to conduct a study to examine the effect of $15 \%$ and $25 \%$ alginate basedmetronidazole gel on A. actinomycetemcomitans bacteria, a periodontal pathogen. The antimicrobial efficacy of these gels was demonstrated to be high. Thus, the findings of the current study could be used as the baseline for further research into the clinical application of alginate-based metronidazole gel as supportive periodontal therapy.

\section{Conclusions}

Alginate-based metronidazole gel was shown to be effective in inhibiting the growth of periodontal pathogens in vitro in the current study. A mean measurement of $\geq 15$ $\mathrm{mm}$ obtained for the three gels was indicative of a strong inhibiting effect on A. actinomycetemcomitans bacteria. The greatest antibacterial activity was attributed to the $25 \%$ alginate-based metronidazole gel, evidenced by the largest recorded zone of inhibition diameter following its use, when compared with the alginatebased $15 \%$ metronidazole and the $25 \%$ non-alginate based metronidazole gel. Thus, alginate can be used as a medium for the topical delivery of a drug because the alginate-based material successfully releases the metronidazole that is present in the alginate gel.

\section{Acknowledgements}

We would like to thank to Faculty of Dentistry and Faculty of Pharmacy Universitas Sumatera Utara.

\section{References}

1. Gopalakrishnan S, Parthiban S, Sudhakar U. Comparative analysis of periodontal pathogens in smokers and non-smokers with chronic periodontitis-A Microbiological Study. Int J Dent Clin. 2012;4(3). 
2. Mane AK, Karmarkar AP, Bharadwaj RS. Anaerobic bacteria in subjects with chronic periodontitis and in periodontal health. J Oral Health Comm Dent. 2009 Sep;3(3):49-51.

3. Paquette David W, Ryan Maria Emanuel, Wilder Rebecca S. Locally delivery antimicrobials: clinical evidance and relevance. J Dent Hyg 2008; 83(3): 10-5.

4. Leiknes T, Leknes KN, Böe OE, Skavland RJ, Lie T. Topical use of a metronidazole gel in the treatment of sites with symptoms of recurring chronic inflammation. J Periodontol. 2007;78(8):1538-44.

5. Dumitrescu AL. The topical use of antibiotics in periodontal pockets. In: Antibiotics and antiseptics in periodontal therapy. Verlag Berlin Heidenberg. Spring; 2011: 171-200.

6. Pejčić A, Kesić L, Obradović R, Mirković D. Antibiotics in the Management of Periodontal Disease. Acta Facultatis Medicae Naissensis. 2010;27(2).

7. Bangun H. Alginat sebagai dasar salep- pelepasan obat, penyerapan air, aliran reologi, dan uji iritasi kulit. Cermin Dunia Kedokteran. 2001; 130:37-41.

8. Aryana SD, Ervina I, Bangun H. Formulation of alginate based metronidazole periodental gel. Asian J Pharmaceut Clin Res. 2014;7(1):224-7.

9. Davis WW, Stout TR. Disc Plate Method of Microbiological Antibiotic Assay I. Factors Influencing Variability and Error. Appl Microbio. 1971 Oct 1;22(4):659-65.

10. Rodrigues AS, Lourenção DS, Lima Neto LG, Pannuti CM, Crespo Hirata RD, Hirata MH, Lotufo RF, De Micheli G. Clinical and Microbiologic Evaluation, by Real - Time Polymerase Chain Reaction, of Non - Surgical Treatment of Aggressive Periodontitis Associated with Amoxicillin and Metronidazole. J Periodontol. 2012;83(6):744-52. 